\title{
Characterization of an intramolecular protein-protein interaction in c-Ets1 and its viral homologue v-Ets
}

\author{
MELANIE SCHMIDT ${ }^{1}$, ANDRÉ MICHAEL SCHMIDT ${ }^{2}$, JOHANNES DIETL $^{1}$ and ULRIKE KAMMERER ${ }^{1}$ \\ ${ }^{1}$ Department of Gynaecology and Obstetrics, University of Würzburg, Josef-Schneider-Strasse 4, 97080 Würzburg; \\ ${ }^{2}$ Casa-Reha Holding GmbH, Hewlett-Packard-Strasse 4, 61352 Bad Homburg v.d.H., Germany
}

Received March 16, 2007; Accepted April 23, 2007

\begin{abstract}
The proto-oncoprotein c-Ets 1 is a well-known transcription factor that belongs to the Ets family and plays a role in haematopoietic differentiation, angiogenesis, and carcinogenesis. Ets family members share a unique DNA binding domain, the Ets domain, and are known to control DNA binding activity and transcriptional activation by autoinhibition. In c-Ets1 the DNA binding domain as well as $\mathrm{N}$-terminal and C-terminal inhibitory domains are involved in autoinhibitory regulation. It has been proposed that intramolecular interactions are part of the autoinhibitory mechanism. We applied a GST pull-down assay as well as a two-hybrid system in yeast to show an interaction between the DNA binding domain of c-Ets 1 and a domain N-terminal thereof. We have mapped the interaction sites within both of the c-Ets 1 domains. Comparison of the analogous intramolecular interaction in c-Ets 1 and in $\mathrm{v}$-Ets revealed that the interaction we detected is stronger in v-Ets than in c-Ets1. In view of previous findings from DNA binding studies, and kinetic experiments as well as structural data, our results suggest a new model as to how intramolecular interactions might participate in the regulation of DNA binding. Binding of c-Ets1 to DNA temporarily changes the intramolecular pattern of interaction in c-Ets1, leading to an increase in affinity of c-Ets1 to DNA. In full-length c-Ets1 the intramolecular interactions re-form spontaneously and the protein-DNA complex dissociates. The interaction we characterize herein might increase the DNA binding affinity temporarily in DNA-bound c-Ets1. In v-Ets in which the C-terminal domain is mutated this interaction appears to lead to strong DNA binding affinity.
\end{abstract}

Correspondence to: Dr Melanie Schmidt, Department of Gynaecology and Obstetrics, University of Würzburg, JosefSchneider-Strasse 4, 97080 Würzburg, Germany

E-mail: melanie_weigand@hotmail.de

Abbreviations: ETS, E26 transformation-specific; GST, glutathioneS-transferase; IPTG, isopropyl-ß-D-thiogalactopyranoside; ONPG, orthonitrophenol; VEGF, vascular endothelial growth factor; VEGFR, vascular endothelial growth factor receptor

Key words: c-Ets1, autoinhibition, GST fusion protein, yeast two-hybrid
Therefore, changes in v-Ets might contribute to the tumorigenic process by altering intramolecular interactions.

\section{Introduction}

The proto-oncoprotein c-Ets1 and its viral homologue v-Ets are members of the Ets family of transcription factors (1). C-Ets1 is expressed by a broad variety of cells. In haematopoietic cells, it contributes to the regulation of cellular differentiation. C-Ets1 plays a role in the regulation of angiogenesis during development, wound healing and tumor angiogenesis. Upon activation by angiogenic factors such as vascular endothelial growth factor (VEGF), endothelial cells transiently produce c-Ets1 resulting in proliferation, migration and invasion $(2,3)$. Together with hypoxia inducible factor (HIF)-2 $\alpha$, c-Ets1 can activate transcription of VEGF receptor-2 (VEGFR-2, KDR, flk-1), by cooperative binding to the VEGFR-2 promotor (4). C-Ets 1 is produced by a variety of solid tumors and by the vascular stroma of cancerous lesions (5). In epithelial cancer cells, c-Ets 1 promotes invasive behaviour and c-Ets 1 expression has been correlated with a poorer prognosis in breast, ovarian, and cervix carcinoma (6-9). C-Ets1 has been described to regulate expression of the matrix metalloproteases MMP1, MMP2, MMP9, and urokinase type plasminogen activator (UPA, 10), as well as that of VEGF (11), VEGF receptor-1 (12), and VEGF receptor-2 (4).

The function of transcription factors is regulated by different mechanisms, in order to control the level of protein synthesis. One frequently occurring mechanism of regulation is autoinhibition. In Ets family members autoinhibition has been found to affect DNA binding activity $(13,14)$. Ets family members share a unique DNA binding domain, the Ets domain, which is highly conserved among species and belongs to the superfamily of winged helix-turn-helix (wHTH) DNA binding proteins (15). In the p68 splice variant of c-Ets1, the DNA binding domain comprises a stretch of 85 amino acids extending from residue 375 to residue 459 and includes three $\alpha$-helices $(\mathrm{H})$ and four $\beta$-strands (S) arranged in the order H1 S1 - S2 - H2 - H3 - S3 - S4. The helix H3 has been shown to interact with the specific DNA core element 5'-GGAA/T-3' (16). Using NMR spectroscopy it has been shown that the helix H3 interacts with the major groove of the DNA core element, whereas the loop between strands 3 and 4 of the $B$-sheet on the one hand and the helices $\mathrm{H} 1-\mathrm{H} 3$ on the other hand 
contribute to DNA interaction with the adjacent minor grooves (17).

$\mathrm{v}$-Ets is the best characterized member of the Ets family and was the first family member to be detected in the E26 avian erythroblastosis virus. The cellular homologue of the viral v-ets is the p68 splice variant of the cellular c-ets 1 gene. v-Ets differs from its cellular homologue by two point mutations and its $\mathrm{C}$-terminal sequence, in which a stretch of 13 amino acids is substituted by 16 completely different amino acids as a result of DNA segment inversion (18). The DNA binding activity of v-Ets is far stronger than that of c-Ets1, which can however be enhanced by deletion of the C-terminal 8 amino acids of c-Ets1 (19).

In c-Ets1, the exon VII domain (amino acids 243-331), an N-terminal regulatory domain that controls the activity of the DNA binding domain, is located adjacent to the DNA binding domain. A C-terminal regulatory unit of exon VII forms part of an autoinhibitory module (20), the inhibitory effect of which is increased by phosphorylation of an N-terminal sequence of the exon VII containing a calcium-responsive phosphorylation site (21). Binding of c-Ets1 to DNA triggers structural changes in the exon VII domain, which in turn release repression of DNA binding $(20,22)$.

DNA binding of c-Ets 1 is repressed by regions $\mathrm{C}$ - and $\mathrm{N}$-terminal of the DNA binding domain that cooperate in destabilizing the protein-DNA complex $(22,23)$. In the Nterminal region the amino acids $325-355$ are necessary to repress DNA binding, whereas in the C-terminal region the amino acids 473-485 are involved (22).

Crystallographic studies of fragments of c-Ets 1 have confirmed that the exon VII domain contains two helices, one of which unfolds upon Ets1 binding to DNA (24). The Cterminal inhibitory region further contains two $\alpha$-helices (25). In earlier studies deletion of an even further N-terminal region (amino acids 207-282) was found to increase DNA binding (19).

Both repression of DNA binding and subsequent release of this repression are induced by conformational changes within c-Ets1. Crystallographic studies suggest that an intramolecular contact between Helix H1 of the ETS domain on the one hand and the $\mathrm{N}$-terminal as well as the C-terminal inhibitory region on the other forms a hydrophobic core and stabilizes the autoinhibitory module $(24,26)$.

We demonstrate herein that intramolecular interactions between different domains of c-Ets1 molecule do indeed exist. We have mapped an interaction between the DNA binding domain of c-Ets1 and a domain N-terminal thereof and show that the mutated viral form exhibits a different pattern of intramolecular interactions. Possibly, the interaction described here forms part of the intramolecular mechanism in c-Ets1 leading to the autoinhibition of DNA binding, which is disrupted in its viral homologue v-Ets.

\section{Materials and methods}

Construction of plasmids for protein interaction assays in solution. For expression of GST fusion proteins, the c-Ets1 DNA binding domain or truncations of it were cloned into the GST fusion vector pGEX-2T (27) using available restriction sites or PCR-mediated strategies. Construction of the plasmids 106, 109, 118 and 119 has been described (28). The amino acid junctions of the GST vector with the Ets sequence (in bold type) are: construct 129: GSPHMLSGSMGPI; construct 130: GSPHMLSGSMPGI; construct 124: GSPHMQSFISW; construct 125: GSPHMQSFISW.

The construct M13 has been published as cetsKS (19). In order to map the intramolecular binding site outside the DNA binding domain of Ets, truncations of c-Ets 1 sequence were constructed by subcloning fragments of cetsKS into PCR II Vector (Stratagene, Heidelberg, Germany) allowing for in vitro translation of proteins. Correct in-frame transition of each sequence in the constructs M36, M40, M41, M57, M52, M39, M55 and 247 was confirmed by DNA sequencing.

GST pull-down assay. For expression and purification of GST fusion proteins, each pGEX construct was used to transform E. coli strain Xl-1 Blue (Stratagene), and resulting transformants were grown overnight in Luria-Bertani broth supplemented with $50 \mu \mathrm{g} / \mathrm{ml}$ ampicillin at $37^{\circ} \mathrm{C}$. When the culture reached an optical density of 0.8 at $600 \mathrm{~nm}$, expression was induced by the addition of IPTG (100 $\mu \mathrm{M}$, Sigma, Deisenhofen, Germany), followed by incubation for further $3 \mathrm{~h}$ at $30^{\circ} \mathrm{C}$. To purify GST proteins, cell lysates were prepared as described by Frangioni and Neel (29) and Smith et al (27). The proteins were incubated with glutathione sepharose 4B resin (Pharmacia, Heidelberg, Germany) for $1 \mathrm{~h}$ at $4^{\circ} \mathrm{C}$, followed by washing with phosphate-buffered saline, $0.05 \%$ Triton X-100 and protease inhibitor cocktail tablets (Roche Diagnostics, Mannheim, Germany).

Expression of c-Ets1 and fragments was generated by in vitro translation with the TNT coupled rabbit reticulocyte lysate system (Promega, Mannheim, Germany) using T7 RNA polymerase and labelling with $100 \mu \mathrm{Ci}\left[{ }^{35} \mathrm{~S}\right]$ methionine/50 $\mu 1$ reticulocyte lysate. Reticulocyte lysate $(5 \mu 1)$ was diluted to $200 \mu 1$ with binding buffer $[150 \mathrm{mM} \mathrm{NaCl}, 50 \mathrm{mM}$ Tris- $\mathrm{HCl}$ ( $\mathrm{pH} 7.6), 0.05 \%$ Triton $\mathrm{X}-100$, and protease inhibitor mix]. The reticulocyte lysate was incubated with $10 \mu 1$ of GST protein for $1 \mathrm{~h}$ at $4^{\circ} \mathrm{C}$. After 5 washes with $1 \mathrm{ml}$ of binding buffer, the complexes were dissociated in $20 \mu 1$ sample buffer [50 mM Tris- $\mathrm{HCl}$ (pH 6.8), 2\% SDS, 5\% ß-mercaptoethanol, $10 \%$ glycerol, $0.02 \%$ bromophenol blue] and separated by SDS-PAGE on $12.5 \%$ acrylamide gels. After staining the gels with coomassie blue, they were treated with dimethyl sulfoxide/2.5-diphenyloxazole for fluorographic exposure, dried under vacuum, and then exposed to X-ray film for 4$12 \mathrm{~h}$.

Construction of plasmids for the yeast two-hybrid system. The previously published reporter construct 27 contains several LexA binding sites, the reporter gene E. coli LacZ and uracil conferring auxotrophy (30).

The bait plasmids carry an HIS3 marker for clonal selection and the sequence of the DNA binding domain of Lex A. Bait plasmid M25 was constructed by inserting the DNA binding domain of c-Ets1 adjacent to the Lex A DNA binding domain in the $10 \mathrm{~kb}$ vector pEG 200+4 (30). Correct in-frame transition was confirmed by DNA sequencing. Plasmid 86 contains the DNA binding domain of Lex A and a fusion protein lacking a binding capacity for DNA or c-Ets1 (28). Plasmid 41 contains the Lex A DNA binding domain only (28). Plasmid pRS423 carries the HIS3 marker but does not encode for a fusion protein (31). Plasmids 86, 41 and pRS423 served as negative 


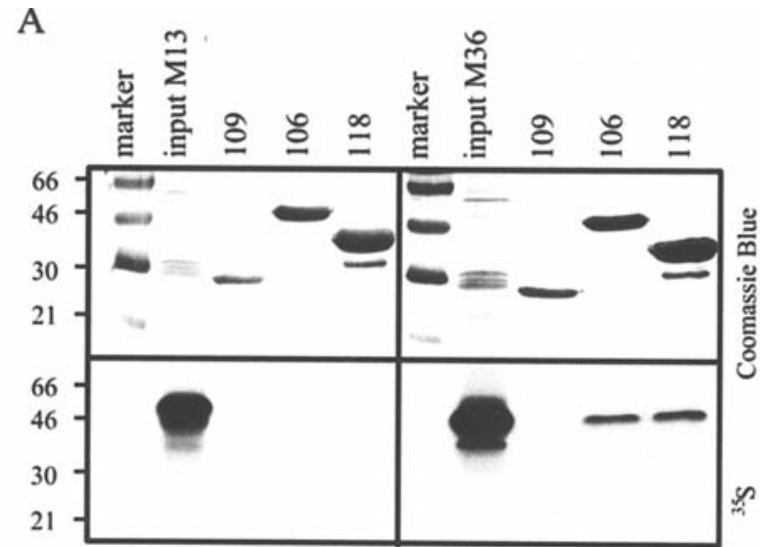

B

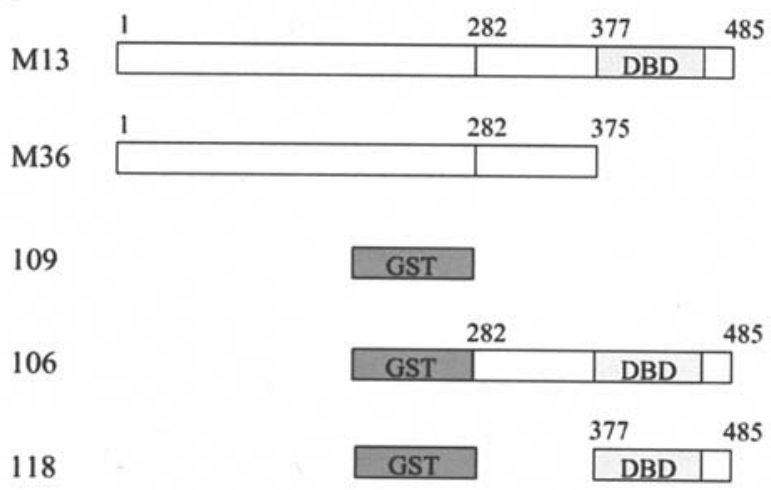

Figure 1. Interaction between the DNA binding domain of c-Ets1 and the $\mathrm{N}$-terminal part of the molecule. In vitro translated $\left[{ }^{35} \mathrm{~S}\right]$ methionine-labelled c-Ets1 (M13) or c-Ets1 lacking the DNA binding domain and the C-terminal domain (M36) were incubated with affinity matrix bound GST (109), DNA binding domain of c-Ets1 fused to GST (118), or an N-terminal extended protein fused to GST (106). Following incubation the proteins were washed, resuspended in SDS sample buffer, and analyzed by SDS-PAGE. Coomassie blue staining and autoradiography of the same gel are shown (A). Molecular mass markers (in $\mathrm{kDa}$ ) are indicated on the right. Schematic drawings of the constructs (B). The first and the last amino acid numbering according to the chicken p68ets 1 present in the deletions is indicated.

controls. Plasmid G1 encoding for a protein fused to the DNA binding domain of Lex A, together with the interacting protein G2 fused to the transactivation domain of VP16, served as a positive control for interaction in the yeast two-hybrid system (Superti-Furga G, personal communication).

The interacting plasmid M17 contains the sequence of c-Ets1 fused to the transactivation domain of VP16. M19 contains the amino acids 1-408 fused to VP16. Correct in-frame transition was confirmed by sequencing.

Expression and transactivation assay in Saccharomyces cerevisiae. For each experiment, the Saccharomyces cerevisiae strain W303-1A (MATa, ho, his3-11, 15; trp1-1; ade2-1; leu23,112; ura3; can1-100) was transformed with three different plasmids using a lithium acetate method as described previously (28). Cells were plated on selective glucose plates lacking histidine, tryptophane, and uracil. After $48 \mathrm{~h}$, when small colonies appeared, they were re-cultivated on selective $\mathrm{X}$-gal containing indicator plates. In the event of interaction between the Lex A DNA binding domain fusion protein and the VP16 fusion protein blue colonies appeared. In addition to visual analysis, single colonies were re-cultivated on selective
A

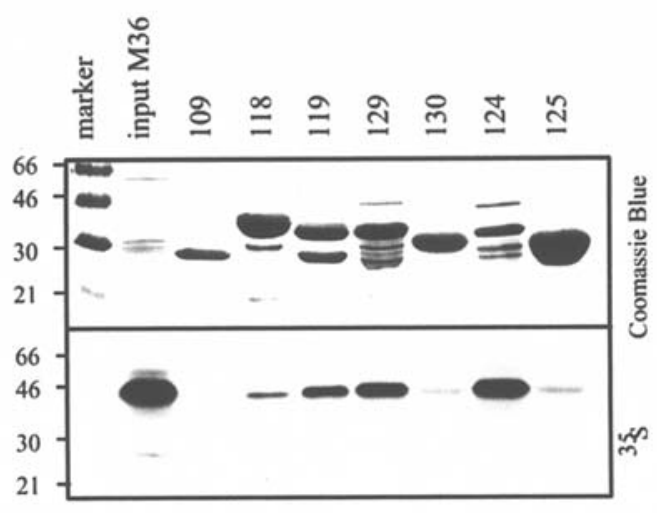

B

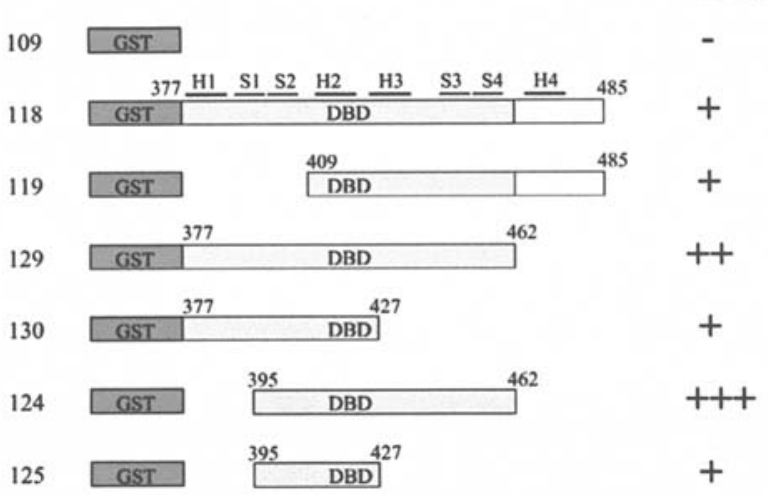

Figure 2. Mapping of the interaction site within the DNA binding domain. To map the interaction site within the DNA binding domain a deletion analysis was performed. $\mathrm{N}$ - and $\mathrm{C}$-terminal deletion mutants of the DNA binding domain of c-Ets 1 fused to GST were tested for association with in vitro translated ${ }^{35}$ S-labelled c-Ets1 lacking the DNA binding domain (M36) and analyzed by SDS-PAGE. Coomassie blue staining and autoradiography of the same gel are shown (A). Molecular mass markers (in $\mathrm{kDa}$ ) are indicated on the right. Schematic drawings of the constructs (B).

plates from which triplicate cultures in $1 \mathrm{ml}$ selective synthetic galactose medium for each condition were inoculated and incubated for $24 \mathrm{~h}$ at $30^{\circ} \mathrm{C}$. Cells were harvested by centrifugation, washed, permeabilized by freezing on dry ice, and ONPG (Sigma) was added. B-galactosidase activity was detected as described previously (28). Enzyme activities were normalized to cell number as measured by the optical density of the cell suspension at $600 \mathrm{~nm}$.

\section{Results}

Identification of an interaction between the DNA binding domain of $c$-Ets 1 and the $N$-terminal part of the molecule. We used a glutathione S-transferase (GST) pull-down assay to investigate whether the DNA binding domain interacts with other domains of c-Ets1. A fusion protein comprising the DNA binding domain and the C-terminal inhibitory domain of c-Ets 1 adjacent to the C-terminus of GST was produced using construct 118 , isolated, immobilized on a glutathione affinity matrix, and incubated with in vitro translated $\left[{ }^{35} \mathrm{~S}\right]$ methionine-labelled full length c-Ets1 (construct M13). In addition, the GST fusion protein was incubated with cEts1 lacking the DNA binding domain (construct M36). As shown in Fig. 1, the c-Ets 1 molecule lacking the DNA 
A

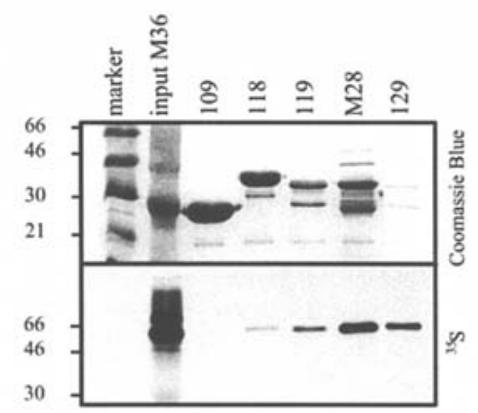

B

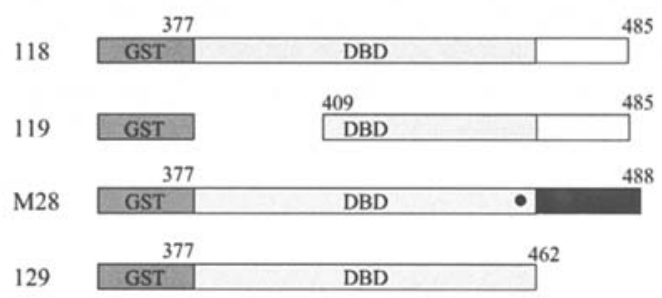

Interaction with M36:

+
+
++
++

Figure 3. The DNA binding domain of v-Ets binds the N-terminal part of the molecule stronger than the DNA binding domain of c-Ets1. The DNA binding domain of v-Ets fused to GST was tested for association with in vitro translated ${ }^{35}$ S-labelled c-Ets 1 lacking the DNA binding domain (M36) analyzed by SDS-PAGE and compared with the DNA binding domain of c-Ets1. Coomassie blue staining and autoradiography of the same gel are shown (A). Molecular mass markers (in $\mathrm{kDa}$ ) are indicated on the right. Schematic drawings of the constructs (B).

binding domain (M36) bound to the DNA binding domain fused to GST. Likewise, the c-Ets 1 molecule lacking the DNA binding domain (M36) bound to an N-terminal extended protein (construct 106). In contrast, in vitro translated full-length c-Ets1 did not bind to the DNA binding domain, and GST alone (109) did not retain c-Ets1.

Mapping the interaction site within the DNA binding domain. We designed a series of deletion mutants of the DNA binding domain fused to GST to localize the interaction site within the DNA binding domain. The fusion proteins were isolated, immobilized, and incubated with in vitro translated $\left.{ }^{35} \mathrm{~S}\right]$ methionine-labelled c-Ets1 lacking the DNA binding domain (M36). As shown in Fig. 2, deletion of the c-Ets1-specific C-terminal 23 amino acids (129) increases the interaction with M36, whereas further C-terminal deletion (130) decreases this interaction. N-terminal deletions up to amino acid 395 do not affect the interaction. The deletion mutant comprising amino acids 395-462 (124) shows the strongest interaction with M36. This mutant contains all four $\beta$-strands and the $\alpha$-helices $\mathrm{H} 2$ and H3. Thus, the helix H1 that has been shown to play a major role in the inhibitory function of the c-Ets1 molecule (24) does not seem to participate in the interaction with the $\mathrm{N}$-terminal part of the molecule. Helix H4/H5 located in the C-terminal region of c-Ets-1, which has also been shown to be part of the inhibitory complex $(22,24)$, seems to disturb the interaction between the DNA binding domain and the remaining molecule, since a deletion leads to an increase of interaction.

The DNA binding domain of $v$-Ets exhibits stronger interaction with the $N$-terminal part of the protein than the DNA binding domain of $c$-Ets 1 . To focus on the role of the C-terminal region
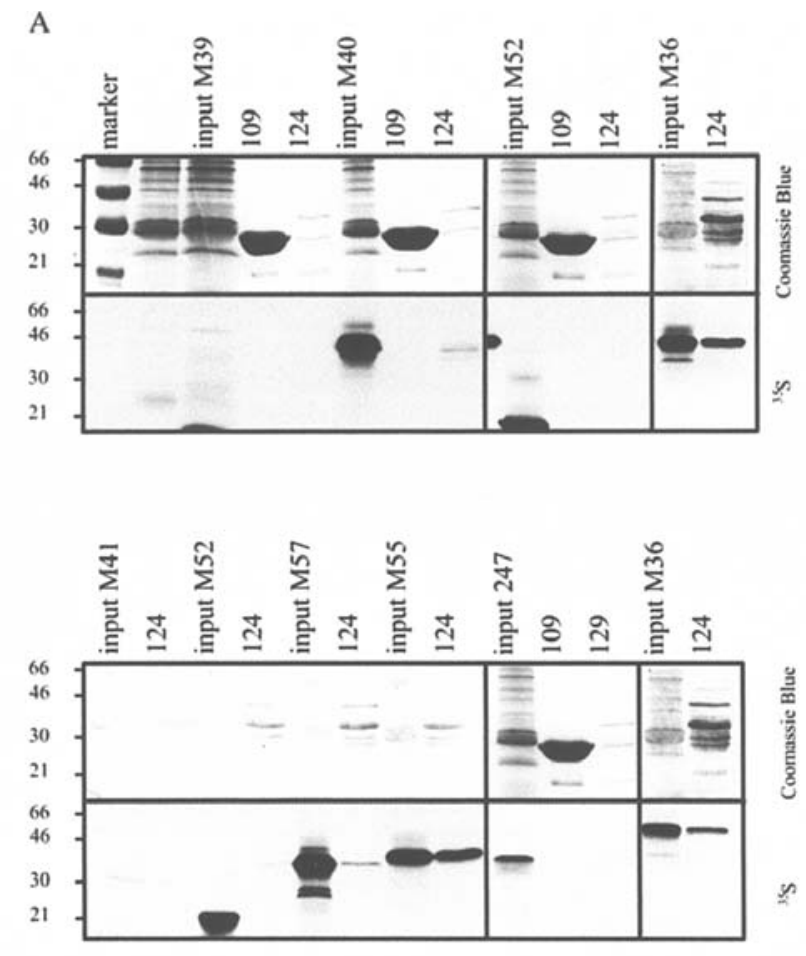

B

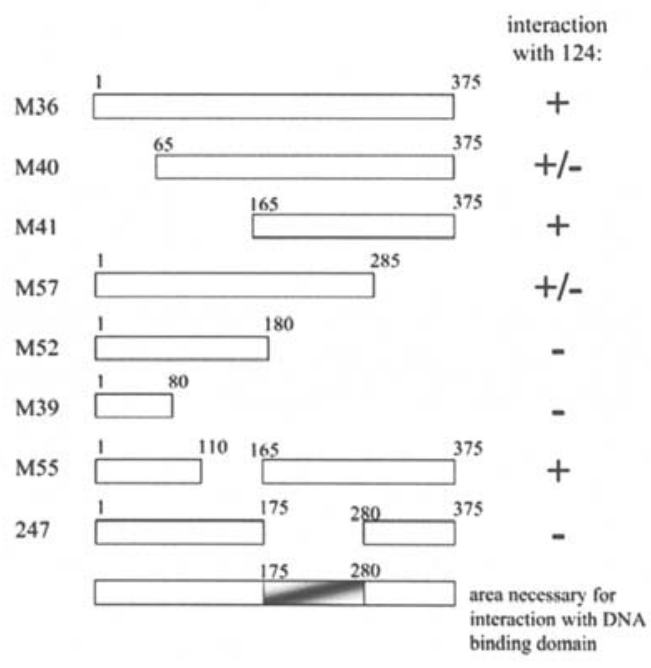

Figure 4. N-terminal localization of the intramolecular interaction. To map the N-terminal interaction site we performed a deletion analysis of c-Ets 1 . $\mathrm{N}$ - and C-terminal deletion mutants of the construct M36 were cloned, ${ }^{35} \mathrm{~S}$-methionine labelled, in vitro translated, and tested for association with the GST fusion protein 124. Coomassie blue staining and autoradiography of the same gel are shown (A). Molecular mass markers (in kDa) are indicated on the right. Schematic drawings of the constructs (B).

in the interaction between the DNA binding domain and the $\mathrm{N}$-terminal part of the molecule, we designed a fusion protein comprising the v-Ets DNA binding domain and GST and tested it for interaction with in vitro translated and radioactively labelled M36. V-Ets differs from c-Ets 1 by the C-terminal amino acids and two point mutations within the DNA binding domain. As shown in Fig. 3, the DNA binding domain of v-Ets (construct M28) interacts more strongly with M36 than the DNA binding domain of c-Ets1 (construct 118). The Cterminal domain of c-Ets 1 therefore seems to inhibit the interaction of the DNA binding domain with the $\mathrm{N}$-terminus 
A

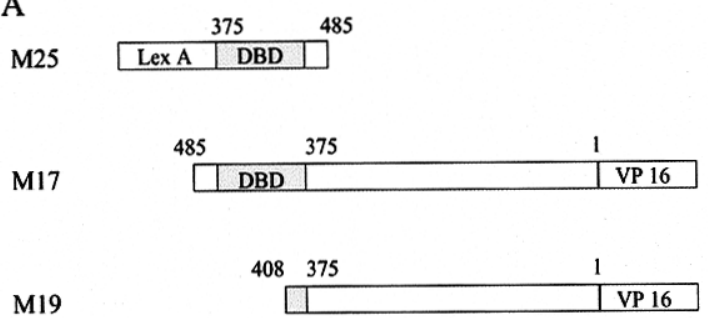

B

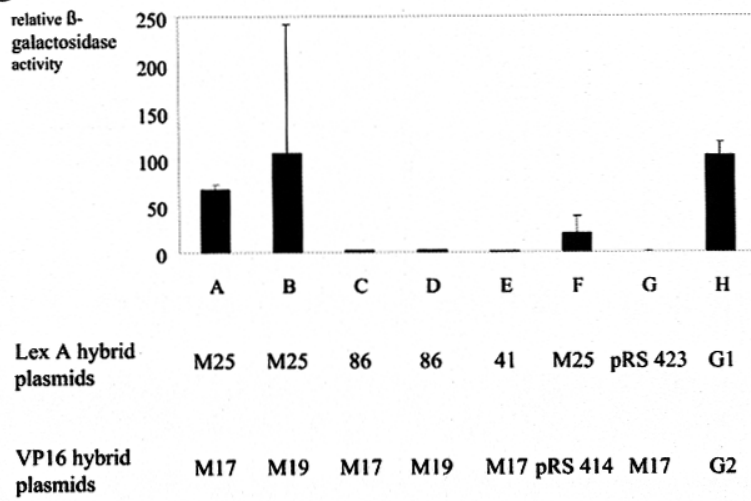

Figure 5. Interaction between the DNA binding domain of c-Ets1 and the $\mathrm{N}$-terminal inhibitory domain in a yeast two-hybrid system (A) Map of the constructs used: M25: DNA binding domain of Lex A fused to the DNA binding domain of c-Ets1; M17: Full-length c-Ets1 fused to the transactivation domain of VP16; M19: c-Ets1 up to amino acid 408 fused to VP16; The receptor plasmid is 27 in all combinations, carrying Lex A binding sites, reporter gene $E$. coli lacZ and URA3 as auxotrophy marker. (B) Reporter activity in response to interaction between the DNA binding domain of c-Ets 1 and the N-terminal part of the molecule. The reporter plasmid 27 was cotransformed with a VP16- and a Lex A fusion protein in the indicated combinations. B-galactosidase activity was measured in a quantitative enzyme assay.

of c-Ets1. This inhibition is not present in v-Ets due to its C-terminal mutations.

Mapping of the N-terminal interaction site of the DNA binding domain. To map the N-terminal interaction site, we constructed several deletion mutants of c-Ets1 lacking the DNA binding domain (construct M36). The proteins were in vitro translated, labelled with $\left.{ }^{[35} \mathrm{S}\right]$ methionine, and incubated with GST fusion protein 124 . The GST fusion protein 124 bound to N-terminal deletions up to amino acid 165 (Fig. 4) and C-terminal deletions up to amino acid 285. Internal deletions lacking the amino acids 110-175 (M55) were bound by GST fusion protein 124 , whereas internal deletions lacking the amino acids 175-280 were not bound. Hence, the amino acids 175-280 seem to be necessary for the interaction between the DNA binding domain of c-Ets1 and an N-terminal area thereof.

Confirmation of the interaction between the DNA binding domain of $c$-Ets 1 and the $N$-terminal part of the molecule in a yeast two-hybrid system. To confirm the interaction we found in a biochemical assay in a biological system, we designed a yeast two-hybrid system using the DNA binding domain of c-Ets1 as bait, fused to the heterologous DNA binding domain of Lex A (fusion protein M25). We constructed two potentially interacting sequences, the full-length c-Ets1 (M17) on the one hand and a c-Ets1 variant lacking the DNA binding domain (M19) on the other, in a yeast expression vector tagged to the transcriptional activation domain from VP16 of Herpes simplex virus. Reporter plasmid, plasmids with Lex A fusion proteins as well as plasmids with VP16 fusion proteins were transfected into a yeast strain. To avoid counter selection of colonies in which protein interactions would result in a growth disadvantage, cells were initially plated on selective glucose medium, where transcription of the fusion proteins was repressed. As soon as small colonies had appeared, they were shifted to galactose medium containing X-Gal as indicator for enzyme activity.

In addition to optical evaluation, the enzyme activity as indicator for interaction between the fusion proteins was quantified using a ß-galactosidase assay. In Fig. 5, the DNA binding domain is shown to interact with full-length c-Ets1 (column A) as well as with the c-Ets1 variant lacking the DNA binding domain (column B). As negative controls, we used a protein fused to Lex $A$ that does not bind c-Ets1 or DNA (plasmid 86, columns C and D), a plasmid carrying Lex A DNA binding domain alone (plasmid 41, column E), and an empty selective plasmid (pRS 414, column F and pRS 423, column G). As a positive control, we used an established yeast two-hybrid system (provided by Superti-Furga G, personal communication, SL1 PL 29b, column H).

Applying this yeast two-hybrid system, we were able to confirm the existence of the intramolecular interaction between the DNA binding domain and an area N-terminal of the DNA binding domain in c-Ets1 (Fig. 5, columns A and B).

\section{Discussion}

Our study provides the first direct evidence for an intramolecular interaction between the DNA binding domain of c-Ets 1 and an inhibitory domain located further N-terminally. We have mapped the interaction sites to the amino acids 175-280 at the N-terminal site and to the amino acids 395-462 within the DNA binding domain. We have also shown that the pattern of intramolecular interaction is different in v-Ets. The presence of $\mathrm{N}$ - and $\mathrm{C}$-terminal inhibitory sequences flanking the ETS domain in c-Ets1 has been described in previous studies (23). Our data support elements of the existing model of c-Ets 1 DNA binding regulation, but in addition provide evidence for further intramolecular interaction that might temporarily stabilize DNA binding of c-Ets1.

The interaction site reported and characterized herein involves the helices $\mathrm{H} 2$ and $\mathrm{H} 3$ as well as the $\beta$-sheet of the DNA binding domain (Fig. 2). NMR studies have revealed that, upon DNA binding, helix $\mathrm{H} 3$ contacts the major groove and that the wing between $\beta$-strand S3, S4 and a loop between helices $\mathrm{H} 2$ and $\mathrm{H} 3$ form further contact sites (32). Therefore, both the $\beta$-sheet and the helix $\mathrm{H} 2$ are exposed upon DNA binding, providing a surface for the interaction with the $\mathrm{N}$ terminal inhibitory domain.

DNA binding studies have shown that full-length c-Ets1 and c-Ets 1 variants comprising N-terminal deletions of c-Ets 1 up to amino acid 207 do not bind DNA, whereas extended deletions lead to DNA binding. The region from amino acid 207-280 has to be intact in order to repress DNA binding (19). Our studies show that the region between amino acids 

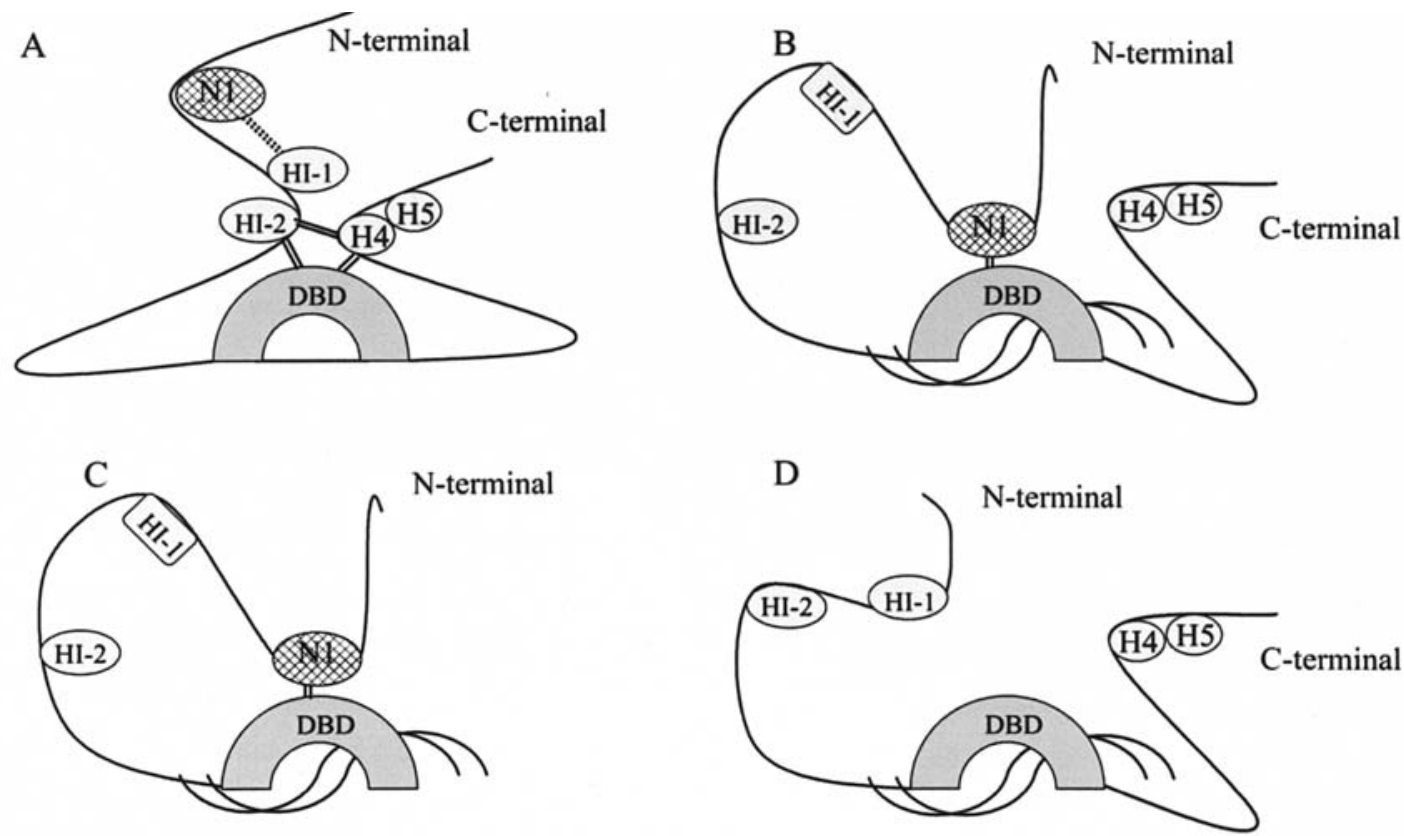

E

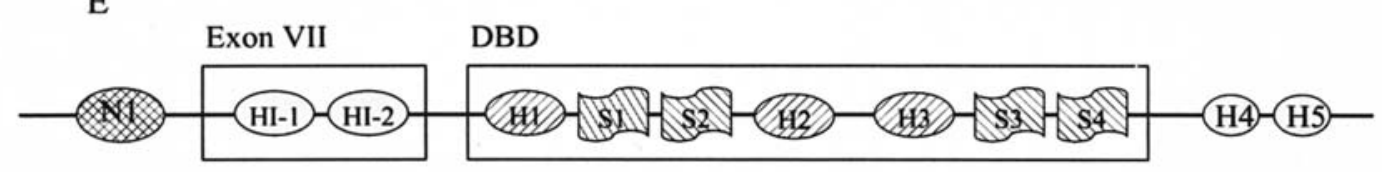

N-terminal

C-terminal

Figure 6. Model of intramolecular interactions regulating DNA binding in c-Ets1. The model shows the full-length c-Ets1 molecule (A) in solution (B) bound to DNA. In solution (A) intramolecular interactions keep the molecule in a closed conformation that impedes DNA binding. The inhibitory interactions involve the inhibitory region encoded by exon VII with the helices HI-1 and HI-2, the C-terminal inhibitory region with helix H4 as well as the DNA binding domain (DBD). Helix HI-1 spontaneously unfolds and releases the inhibitory interaction. This conformational change allows the DBD to bind DNA. DNA binding is temporarily stabilized by the interaction between the N-terminal inhibitory region (NI) and the DNA binding domain (B). This conformational status allows transcriptional activation and is spontaneously replaced by the closed confirmation triggered by reformation of the helix HI- 1 . The correct regulation can only take place within the full-length molecule. Deletion of the C-terminus affects the inhibitory interaction and leads to increased DNA binding (C). Deletion of the N-terminal inhibitory area N1 does not allow correct formation of the hydrophobic core (D). Both, deletion of the C-terminus and of N1 result in increased DNA binding and transcriptional activation. Arrangement of Exon VII, the DNA binding domain and known secondary structures within c-Ets1 (E)

175 and 280 has to be intacted to interact with the DNA binding domain. This correlates with the area shown to inhibit DNA binding. DNA binding is also enhanced by deletion or exchange of the C-terminal 8-16 amino acids as in v-Ets (19). Our data indicate that deletion or exchange of the C-terminus increases the interaction between the DNA binding domain and the $\mathrm{N}$-terminal inhibitory domain. Combining previous DNA binding studies with our findings gives rise to a new model for c-Ets1 autoinhibition. Deletion of the N-terminal area prevents the intramolecular interaction with the DNA binding domain and leads to DNA binding of cEts1. Deletion of the C-terminal 8-16 amino acids results in a stronger intramolecular interaction but also increases DNA binding. An explanation for this inconsistency could be that the inhibitory domains on both sides of the DNA binding domain are independent in terms of function but cooperate in the inhibitory mechanism. There are several known inhibitory regions within c-Ets1 that repress DNA binding. An area Nterminal of the DNA binding domain between amino acids 175 and 285 was first identified to inhibit DNA binding (N1) by Lim et al (19). This area is identical with the area we show here to interact with the DNA binding domain. A second inhibitory region between amino acids 325 and 375 was identified by Petersen et al (20). It lies within the area encoded by Exon VII and contains two $\alpha$-helices (HI-1 and HI-2). A third inhibitory domain with two $\alpha$-helices was identified C-terminal of the DNA binding domain (H4/H5). A structural alliance between helix $\mathrm{H} 4 / \mathrm{H} 5$ and the first helix within the DNA binding domain $\mathrm{H} 1$ was shown by nuclear Overhauser effect spectroscopy $(15,33)$. As shown by crystallographic studies the helices HI-1, HI-2 and H4/H5 inhibit DNA binding of Ets proteins by interacting with helix H1 of the Ets domain to form a hydrophobic core (24). These intramolecular interactions transiently keep the Ets domain in a closed conformation that prevents DNA binding. As the inhibitory helix HI-1 spontaneously unfolds and forms a random coil (20) the closed conformation is relieved and cEts 1 can bind DNA. These structural changes allow Ets proteins to modulate DNA binding and thereby transcriptional activity (24).

The N-terminal interaction site we identified and characterized (N1) is located further N-terminal than the inhibitory sequences HI-1 and HI-2. The interaction of N1 with the DNA binding domain is increased upon deletion or mutation of the $\mathrm{C}$-terminus and the deletion of $\mathrm{N} 1$ results in increased DNA binding (19). Thus, we assume that the interaction between $\mathrm{N} 1$ and the DNA binding domain counteracts the interaction between HI-1 and HI-2 and the 
DNA binding domain and temporarily stabilizes DNA binding of c-Ets1 (Fig. 6). In absence of DNA binding the hydrophobic core between HI-1, HI-2, H4/H5 and the DNA binding domain leads to a closed confirmation of c-Ets1. Unwinding of HI-1 opens the confirmation and allows subsequent DNA binding of c-Ets 1 and transcriptional activation. The open confirmation of c-Ets1 upon DNA binding is temporary and might be stabilized by interaction of N1 with the DNA binding domain. The equilibrium between the closed confirmation of c-Ets 1 in solution and the open confirmation of c-Ets1 upon DNA binding is only well regulated in the full-length molecule. Interference, such as deletions or mutations in v-Ets, shifts the equilibrium towards increased DNA binding and thus to uncontrolled transcriptional activation. Such a scenario could form uncontrolled mechanisms by which v-Ets induces tumorigenesis. In further studies it needs to be clarified whether the $\mathrm{N}$-terminal inhibitory regions $\mathrm{N} 1$ and exon VII are functionally coupled. It is still unclear if the inhibitory region N1 supports correct formation of the hydrophobic core. It also remains to be investigated how interactions with other proteins affect conformational changes within c-Ets 1 and what role the inhibitory domain N1 plays in this context.

\section{Acknowledgements}

We thank Michael Sieweke and Thomas Graf for their generous help and for the opportunity to work in their laboratory. We also thank Kurt Weigand for valuable discussions and Marianne Madlener for critical review of the manuscript. This study was supported in part by the European Molecular Biology Laboratory and the Steiner Foundation.

\section{References}

1. Sharrocks AD, Brown AL, Ling Y and Yates PR: The ETSdomain transcription factor family. Int J Biochem Cell Biol 29: 1371-1387, 1997

2. Stenmark KR and Mecham RP: Cellular and molecular mechanisms of pulmonary vascular remodelling. Annu Rev Physiol 59: 89-144, 1997.

3. Dittmer J: The Biology of the Ets1 proto-oncogene. Mol Cancer 2: 29, 2003.

4. Elvert G, Kappel A, Heidenreich R, Engelmeier U, Lanz S, Acker T, Rauter M, Plate K, Sieweke M, Breier B and Flamme I: Cooperative interaction of hypoxia-inducible factor-2alpha (HIF-2alpha) and Ets-1 in the transcriptional activation of vascular endothelial growth factor receptor-2 (Flk-1). J Biol Chem 278: 7520-7530, 2003.

5. Wernert N, Gilles F, Fafeur V, Bouali F, Raes MB, Pyke C, Dupressoir T, Seitz G, Vandenbunder B and Stehelin D: Stromal expression of c-Ets1 transcription factor correlates with tumor invasion. Cancer Res 54: 5683-5688, 1994.

6. Takai N, Miyazaki T, Fujisawa K, Nasu K and Miyakawa I: c-Ets 1 is a promising marker in epithelial ovarian cancer. Int $\mathrm{J}$ Mol Med 9: 287-292, 2002.

7. Fujimoto J, Aoki I, Toyoki H, Khatun S and Tamaya T: Clinical implications of expression of ETS-1 related to angiogenesis in uterine cervical cancers. Ann Oncol 13: 1598-1604, 2002.

8. Span PN, Manders P, Heuvel JJ, Thomas CM, Bosch RR, Beex LV and Sweep CG: Expression of the transcription factor Ets- 1 is an independent prognostic marker for relapse-free survival in breast cancer. Oncogene 21: 8506-8509, 2002.

9. Davidson B, Reich R, Goldberg I, Gotlieb WH, Kopolovic J, Berner A, Ben-Baruch G, Bryne M and Nesland JM: Ets-1 messenger RNA expression is a novel marker of poor survival in ovarian carcinoma. Clin Cancer Res 7: 551-557, 2001.

10. Sementchenko VI and Watson DK: Ets target genes: past present and future. Oncogene 19: 6533-6548, 2000.
11. Tomita N, Morishita R, Taniyama Y, Koike H, Aoki M, Shimizu H, Matsumotot K, Nakamura T, Kaneda Y and Okihara T: Angiogenic property of hepatocyte growth factor is dependent on upregulation of essential transcription factor for angiogenesis, ets-1. Circulation 107: 1411-1417, 2003.

12. Wakiya K, Begue A, Stehelin D and Shibuya M: A cAMP response element and an Ets motif are involved in the transcriptional regulation of flt-1 tyrosine kinase (vascular endothelial growth factor receptor 1) gene. J Biol Chem 271: 30823-30828, 1996.

13. Janknecht $R$ and Nordheim A: Gene regulation by Ets proteins. Biochem Biophys Acta 1155: 346-356, 1993.

14. Greenall A, Willingham N, Cheung E, Boam DS and Sharrocks AD: DNA binding by the ETS-domain transcription factor PEA3 is regulated by intramolecular and intermolecular protein-protein interactions. J Biol Chem 276: 16207-16215, 2001.

15. Donaldson LW, Petersen JM, Graves BJ and McIntosh LP: Secondary structure of the ETS domain places murine Ets- 1 in the superfamily of winged helix-turn-helix DNA-binding proteins. Biochemisty 33: 13509-13516, 1994.

16. Nye JA, Petersen JM, Gunther CV, Jonsen MD and Graves BJ: Interaction of murine ets-1 with GGA-binding sites establishes the ETS domain as a new DNA-binding motif. Genes Dev 6: 975-990, 1992.

17. Werner MH, Clore GM, Fisher CL, Fisher RJ, Trinh L, Shiloach J and Gronenborn AM: Correction of the NMR structure of the ETS1/DNA complex. J Biomol NMR 10: 317-328, 1997.

18. Lauterberger JA and Papas TS: Inversion of a chicken ets-1 protooncoprotein segment in avian leukaemia virus E26. J Virol 67: 610-612, 1996.

19. Lim F, Kraut N, Frampton J and Graf T: DNA binding by c-Ets-1 but not v-Ets, is repressed by an intramolecular mechanism. EMBO J 11: 543-652, 1992.

20. Petersen JM, Skalicky JJ, Donaldson LW, McIntosh LP, Alber T and Graves BJ: Modulation of transcription factor Ets-1 DNA binding: DNA-induced unfolding of an alpha helix. Science 269: 1866-1869, 1995.

21. Rabault B and Ghysdael J: Calcium-induced phosphorylation of ETS1 inhibits its specific DNA binding activity. J Biol Chem 269: 28143-28151, 1994.

22. Jonsen MD, Petersen JM, Xu Q-P and Graves B: Characterisation of the cooperative function of inhibitory sequences in Ets-1. Mol Cell Biol 16: 2065-2073, 1996.

23. Skalicky JJ, Donaldson LW, Petersen JM, Graves BJ and McIntosh LP: Structural coupling of the inhibitory regions flanking the ETS-domain of murine Ets-1. Protein Sci 5: 296-309, 1996.

24. Garvie CW, Pufall MA, Graves BJ and Wolberger C: Structural analysis of the autoinhibition of Ets-1 and its role in protein partnerships. J Biol Chem 277: 45529-45536, 2002.

25. Garvie CW, Hagman J and Wolberger C: Structural studies of Ets-1/Pax5 complex formation on DNA. Mol Cell 8: 1267-1276, 2001.

26. Wang H, McIntosh LP and Graves BJ: Inhibitory module of Ets-1 allosterically regulates DNA binding through a dipolefacilitated phosphate contact. J Biol Chem 277: 2225-2233, 2002.

27. Smith DB, Berger LC and Wildeman AG: Modified glutathione S-transferase fusion proteins for simplified analysis of proteinprotein interactions. Nucleic Acids Res 21: 359-360, 1993.

28. Sieweke MH, Tekotte H, Frampton J and Graf T: MafB is an interaction partner and repressor of Ets-1 that inhibits erythroid differentiation. Cell 85: 49-60, 1996.

29. Frangioni JV and Neel BG: Solubilization and purification of enzymatically active glutathione S-transferase (pGEX) fusion proteins. Anal Biochem 210: 179-187, 1993.

30. Golemis EA and Brent R: Fused protein domains inhibit DNA binding by LexA. Mol Cell Biol 1: 3006-3014, 1992.

31. Sikorski RS and Hieter P: A system of shuttle vectors and yeast host strains designed for efficient manipulation of DNA in Saccharomyces cerevisiae. Genetics 122: 19-27, 1989.

32. Kodandapani R, Pio F, Ni C-Z, Piccialli G, Klemsz M, McKercher S, Maki RA and Ely KR: A new pattern for helixturn-helix recognition revealed by the PU.1 ETS-domain DNA complex. Nature 380: 456-460, 1996.

33. Donaldson LW, Petersen JM, Graves BJ and McIntosh LP Solution structure of the ETS domain from murine Ets-1: a winged helix-turn-helix DNA binding motif. EMBO J 15: 125-134, 1996. 